\title{
Quality of Life, Cortisol Blood Levels and Exercise in Older Adults: Results of a Randomized Controlled Trial
}

\author{
Gioia Mura ${ }^{1, *}$, Giulia Cossu ${ }^{1}$, Gian M. Migliaccio ${ }^{2}$, Claudio Atzori ${ }^{3}$, Antonio E. Nardi ${ }^{4}$, \\ Sergio Machado ${ }^{4,5}$ and Mauro G. Carta ${ }^{1}$
}

\begin{abstract}
${ }^{I}$ Department of Public Health, Clinical and Molecular Medicine, University of Cagliari, Italy; ${ }^{2}$ CONI Italian Olympic Committee, Sardinia, Italy; ${ }^{3}$ CMT Medical Analysis Laboratory, Cagliari, Italy; ${ }^{4}$ Panic and Respiration Laboratory, Institute of Psychiatry of Federal University of Rio de Janeiro (IPUB/UFRJ), Brazil; National Institute of Translational Medicine (INCT-TM); ${ }^{5}$ Physical Activity Neuroscience Laboratory (LABNAF), Physical Activity Sciences Postgraduate Program of Salgado de Oliveira University (PPGCAF/UNIVERSO), Niterói, Brazil
\end{abstract}

\begin{abstract}
Introduction: Cortisol plays a central role in the stress response; while high stress can determine physical and psychological impairment, moderate stress, with a mild increase in cortisol level, may have a positive effect on coping and physical performance. This trial attempted to determine whether cortisol levels were associated with Quality of Life (QoL) in a sample of elderly subjects undertaking an exercise program. Methods: 42 subjects aged $\geq 65$ years were randomly assigned in a 1:1 fashion either to a vigorous physical activity (VAG: $\mathrm{N}=21$ ) or to a postural gimnastic group (PGG: N=21). Differences between the two groups in QoL (on SF-12), and blood cortisol levels were assessed by ANOVA at different times. Results: In both the VAG and PGG, cortisol levels rose at the end of the trial, with statistically significant differences as compared to the baseline. QoL at the end of the trial was higher than in the national normative sample. Cortisol and QoL in both groups decreased slightly 12 weeks after the end of the trial (T2); however, only in the VAG did the difference from the initial level remain statistically significant. At T1 and T2, subjects with higher SF-12 scores were found in subsamples in both groups with cortisol levels moderately increased (between $200 \mathrm{and} 300 \mathrm{mg} / \mathrm{ml}$ ). Conclusion: In a sample of elderly subjects undergoing two different kinds of exercise, a better perception of Quality of Life was associated with a moderate, non-pathological increase in cortisol. The results need to be confirmed by trials on larger samples.
\end{abstract}

Keywords: Cortisol, elderly, exercise, quality of life.

\section{INTRODUCTION}

A moderate response to stress is adapting for human survival. The activation of the hypothalamic-pituitaryadrenocortical (HPA) axis, inducing the secretion of glucocorticoids, plays a central role in the stress response, as well as interacting with other systems involved in this response: endocannabinoids; the immune response (cytokines have been implicated in response to long-term stress); the release of catecholamines by means of adrenergic neurotransmission [1].

The activation of these pathways leads to a fast physical and psychological response and, in adaptive conditions, produces long-term positive modifications in the brain [2]. These long-term adaptive mechanisms allow humans to effectively deal again with similar requests. Thus, a moderate level of stress exerts a favorable effect on coping mechanisms. By contrast, exposure to severe, traumatic, or chronic stress might have the opposite effect and may result in memory loss, cognitive impairment and stress-related psychopathologies such as anxiety or depressive disorders and

*Address correspondence to this author at the Department of Public Health, Clinical and Molecular Medicine, University of Cagliari, Italy; Tel: +39070 6093498; Fax: +39070 6093498;

E-mails: mura.gioia@virgilio.it and gioia.mura@yahoo.it post-traumatic stress disorder (PTSD) [2, 3]. Great effort has been devoted to understanding the negative effects of chronic stress. Nevertheless, little has been done to identify how stress promotes coping mechanisms in the brain. These features will provide critical information to improve adjustment strategies in both normal and pathological conditions.

The level of blood cortisol is a milestone in monitoring the stress response. However, the relationship among stress, well-being, and cortisol levels is very complex [4].

The importance of understanding the mechanisms underlying well-being in the elderly has currently been emphasized; nevertheless, little is known about the relationship between well-being and blood cortisol in older people.

Severe stress was shown to be associated with a significant increase in the cortisol/dehydroepiandrosterone (DHEA) ratio in elderly people [5]. During exposure to severe stress, exercise may protect the elderly from an increased cortisol/DHEA ratio [5]. However, in elderly people, low cortisol levels during the day were related with worst performance on the Berg Balance Scale and lower handgrip strength, showing a correlation between the levels of cortisol and physical functioning during the aging [6]. Presumably, according to Seyle's original theories about eustress and distress [7], if a strong stress can induce excessively high levels of cortisol, 
moderate stress can be adaptive, stimulating a moderate but not excessive cortisol level.

Quality of Life (QoL) is a subjective concept of wellbeing depending on several factors, such as concomitance of illness, income and stress. The subjective perception of QoL is now considered of great relevance in measuring the level of appreciation of daily life in elderly patients with or without health problems, particularly in those with chronic conditions $[8,9]$. It has become central in evaluating the effectiveness of treatment as well [10].

The perception of QoL improves in women with depression following a fitness program $[11,12]$. In a recent study, we showed that a high QoL was associated with exercise in the elderly, and a vigorous physical activity program might be associated with better maintenance of results over time as compared to a postural gymnastic program [13].

The present paper sought to determine whether, in the same sample used in the above-cited study [13], cortisol levels taken before, during and after the trial were related to the perception of QoL.

The hypothesis is that the positive changes in the perception of QoL induced by exercise in a sample of older people could be related to exercise-induced changes in blood cortisol.

\section{METHODS}

The study was carried out as part of the "A Chent'Annos in Salude" (a typical Sardinian saying, which could be translated as "I hope you'll live a hundred years in good health") trial, a prospective population-based study aiming to verify the physiological modifications induced by exercise in the elderly, carried out by the Italian Olympic Committee (CONI) Sardinia, approved by CONI Sardinia and conducted at the Italian Olympic Committee in Cagliari, Italy. The methods were described in a previous paper [13]; briefly, the study was a 12-week randomized controlled trial, in which participants were volunteers aged $\geq 65$ years, recruited by announcements in a local newspapers, general practitioners, flyers in pharmacies. About 350 people manifested their interest to participate, and they were contacted by phone by the research team for further information about the study; more or less 180 people agreed to participate and underwent a detailed medical evaluation trough the list of inclusion/exclusion criteria.

Inclusion required at least one criterion between sedentariness (defined according the Physical Activity Guidelines for Older Adults as less than 30 minutes/day of moderate physical activity performed on five or fewer days/week [14]) and dysmetabolism (defined according to the American Hearth Association criteria [15]). Exclusion criteria were the presence of: any cardiovascular, osteoarticular, neurological or oncological disease that could be a contraindication to perform a stress test or that could be incompatible with exercise; moderate to severe anemia $(\mathrm{Hb}<10 \mathrm{mg} / \mathrm{dl})$; obesity with BMI $>35$. Moreover, only subjects without difficult to reach the gym where the study was carried out were included.

After signing a written informed consent, all participants underwent a thorough medical examination, that included: anthropometric measurements; electrocardiogram, systolic/diastolic blood pressure measurement, spirometry at rest and under stress test; blood sampling for complete blood count, glycaemia, total cholesterol, high-density and lowdensity lipoproteins, triglycerides, azotemia, creatinine, cortisol. Following this check-up, participants were randomly assigned in a 1:1 fashion to two different groups: VAG (Vigorous Activity Group) and PGG (Postural Gymnastic Group).

The study started in April 2013 (T0) and ended in July 2013 (T1). Twelve weeks later, participants were submitted to follow-up and assessed again (T2).

\section{Fitness Programs}

According to ACSM guidelines [16], Physical Activity (PA) was established as between $60 \%$ and $84 \%$ of the Heart Rate Reserve (HRR), continuously monitored during activity with the Polar T31 Coded $^{\mathrm{TM}}$ heart-rate monitor, and also transmitted by a telemetry system $\left(\right.$ Hosand $^{\circledR}$ ) to fitness professionals. The individual HRR for each participant was assessed according to the Estimated Maximal Heart Rate Formula [17], where HRmax = 206.9 - (0.67 x Age). Baseline HR was registered for all participants for three days, in the morning immediately after waking, and the mean data utilized.

PA for the VAG consisted of three phases: 1) warm-up, up to $10 \mathrm{~min}$, up to $60 \%$ of HRR; 2) active phase, 45 -min, from $>60 \%$ to $84 \%$ and HRR 3) cool-down, up to $10-\mathrm{min}$, $<60 \%$ of HRR. The Active Phase was designed as a mixture of aerobic and anaerobic exercises.

PA for the PGG was designed to maintain the heart rate $<$ to $50 \%$ of HRR. It included static and dynamic exercise for postural control and spine mobility exercise.

PA was conducted by fitness professionals with degrees in Sports and Physical Education and continuously monitored by a supervisor responsible for the HRR activity level.

\section{Outcome Measurements}

A direct chemiluminescence assay procedure using commercially-available kits was used to determine plasma cortisol levels, with cortisol sensitivity $=2.0-750 \mathrm{ng} / \mathrm{ml}$. Plasma collection took place between 8 a.m. and 9 a.m., three times for each participant (T0, T1 and T2). In adults, normal cortisol levels at 8 a.m. are between 100 and 250 $\mathrm{mg} / \mathrm{ml}$; a level between 250 and 300 can be considered a moderate, non-pathological increase. Laboratory technicians were blinded to treatment allocation.

Quality of Life was assessed using the Short Form Health Survey (SF-12) [18]. The SF-12 includes the following domains: physical activity, physical health limitations on roles or activities, emotional state, physical pain, general state of health, vitality, social activity and mental health. The measurement period was the month preceding the assessment. Higher scores on the SF-12 match the best conditions in QoL. SF-12 rates were registered at T1 and T2.

\section{Statistical Analysis}

Scores on the SF-12 for the two groups were compared with the normative score for a large national sample stan- 
dardized by age and sex, drawn from a national survey in Italy [19] by ANOVA 1-way statistics.

To test differences between the two groups (VAG and PGG) on the SF-12 and cortisol over time, we conducted variance analysis (ANOVA) at different times.

Chi square with Yates' correction was conducted to test the difference in SF-12 scores between subgroups with cortisol levels $\geq 200 \mathrm{mg} / \mathrm{ml}$ compared with those with cortisol $<200 \mathrm{mg} / \mathrm{ml}$, and subjects with cortisol levels $\geq 200$ and $\leq 300 \mathrm{mg} / \mathrm{ml}$ compared with those with cortisol levels $<200$ or $>300 \mathrm{mg} / \mathrm{ml}$.

\section{Ethical Aspects}

Each subject in the study was identified by a code number not ascribable to their name by researchers. Informed consent for the use of anonymous data for scientific purposes was obtained from each patient. The study was approved by the Board of the "Comitato Olimpico Nazionale Italiano" (CONI) of the Sardinian Region.

\section{RESULTS}

21 subjects were assigned to treatment with the VAG (12 males, 9 females), mean age $69.24 \pm 3.9 ; 21$ subjects were assigned to treatment with the PGG (14 males and 7 females, mean age $70.0 \pm 5.3$ ).

In the VAG, 3 subjects reported at least one previous depressive episode, one of them being treated with antidepressant drugs. Two other subjects were taking benzodiazepines. In the PGG, one person reported at least one previous depressive episode. Another subject was taking antidepressants and benzodiazepines. One participant in the PGG was undergoing chronic therapy with corticosteroids; nevertheless, as this participant's cortisol level was in the normal range, we did not remove it.

In the VAG, 11 subjects were receiving pharmacological treatment, in 7 cases multiple-drug treatment. In the PGG, 15 subjects were taking medication, in 11 cases multiple drugs. In the VAG, concomitant organic diseases were: hypertension ( 8 subjects), hypercholesterolemia (3 subjects) and os- teoporosis ( 2 subjects); in the PGG, 8 subjects were suffering from hypertension, 5 from diabetes mellitus (type 1 in one case), 4 from hypercholesterolemia, 4 from non-severe heart disease (heart failure, atrial fibrillation, aorta-coronary bypass), 3 from thyroid diseases (post-surgical hypothyroidism, Hashimoto's thyroiditis) and 2 from musculoskeletal diseases (arthritis, osteoporosis).

Two subjects in the VAG group and one in the PGG group dropped out of the study.

Table 1 shows blood cortisol levels during the trial. In both groups, cortisol levels rose at the end of the trial as compared to the baseline, with statistically significant differences. Cortisol in both groups decreased slightly 12 weeks after the end of the trial (T2); however, the difference from the initial level in the VAG sample remained statistically significant, while the cortisol level in the PGG group did not differ from the initial level.

Table 2 shows SF-12 scores at T1 and T2 for the VAG and PGG groups as compared to the normative Italian sample. At the end of the study (T1), the level of QoL measured by means of SF-12 scores was better in both the VAG and PGG groups than in the normative standardized sample. SF-12 scores for the two groups decreased slightly 12 weeks after the end of the trial; however, the difference between the VAG and the normative sample remained statistically significant (ANOVA 1 way: $F=5.52 ; \mathrm{p}=0.019$; df $1,703,704$ ), while the QoL level in the PGG group did not differ from the normative sample (ANOVA 1 way: $F=3.10 ; p=0.079$; df $1,703,704)$.

Table $\mathbf{3 a}$ and $\mathbf{3} \mathbf{b}$ respectively show the distribution of subjects at T1 and T2 with an SF-12 score higher than average, plus one standard deviation from the distribution on the national normative sample standardized by sex and age [16], between those with cortisol levels ranging from 200 to 300 $\mathrm{mg} / \mathrm{ml}$ and those with cortisol levels $<200$ or $>300 \mathrm{mg} / \mathrm{ml}$. At $\mathrm{T} 1$, subjects in both groups $(\mathrm{N}=20)$ with cortisol level $\geq 200 \mathrm{mg} / \mathrm{ml}$ showed no difference in SF-12 scores as compared with subjects with less than $200 \mathrm{mg} / \mathrm{ml} \quad(\mathrm{N}=19)$ (40.5 \pm 4.6 vs. $39.0 \pm 5.4$, df $1,37,38, F=0.875, p=0.356)$. At $\mathrm{T} 2$, subjects with cortisol level $\geq 200 \mathrm{mg} / \mathrm{ml}$ in both groups $(\mathrm{N}=20)$ showed higher levels on $\mathrm{SF}-12$ scores than subjects

Table 1. Cortisol blood levels before, immediately after the trial and 12 weeks later.

\begin{tabular}{|c|c|c|c|c|c|}
\hline Group & T0 & T1 & T2 & $\begin{array}{c}\text { T0 vs. T2 } \\
\text { df 1,703,704 }\end{array}$ & $\begin{array}{c}\text { T0 vs. T1 } \\
\text { df 1,703,704 }\end{array}$ \\
\hline \hline VAG $(\mathrm{N}=21)$ & $156.99 \pm 37.03$ & $188.36 \pm 38.56$ & $191.15 \pm 50.08$ & $\mathrm{~F}=6.13, \mathrm{P}=0.016$ & $\mathrm{~F}=7.23, \mathrm{P}=0.010$ \\
\hline PGG $(\mathrm{N}=21)$ & $161.99 \pm 49.99$ & $233.74 \pm 79.74$ & $188.55 \pm 55.80$ & $\mathrm{~F}=12.205, \mathrm{P}=0.001$ & $\mathrm{~F}=2.639, \mathrm{P}=0.112$ \\
\hline
\end{tabular}

Table 2. SF-12 score immediately after the trial and 12 weeks later as compared with Normative Italian Scores.

\begin{tabular}{|c|c|c|c|c|c|}
\hline Group & $\begin{array}{c}\text { Normative Italian } \\
\text { Sample }\end{array}$ & T1 & T2 & $\begin{array}{c}\text { T1 vs. Normative } \\
\text { df 1,703,704 }\end{array}$ & $\begin{array}{c}\text { T2 vs. Normative } \\
\text { df 1,703,704 }\end{array}$ \\
\hline \hline VAG (N=21) & $35.7 \pm 6.8$ & $40.1 \pm 4.9$ & $39.3 \pm 4.8$ & $F=8.24 ; \mathrm{p}=0.004$ & $\mathrm{~F}=5.52 ; \mathrm{p}=0.019$ \\
\hline PGG $(\mathrm{N}=21)$ & $35.7 \pm 6.8$ & $39.1 \pm 5.1$ & $38.4 \pm 5.29$ & $\mathrm{~F}=4.91 ; \mathrm{p}=0.027$ & $\mathrm{~F}=3.10 ; \mathrm{p}=0.079$ \\
\hline
\end{tabular}


with less than $200 \mathrm{mg} / \mathrm{ml}(\mathrm{N}=19)(41.2 \pm 4.8$ vs. $38.1 \pm 4.6$, df $1,37,38, F=4.424, p=0.047)$. Subjects with more than 200 $\mathrm{mg} / \mathrm{ml}$ of cortisol numbered $7(36.8 \%)$ at $\mathrm{T0} ; 17(43.6 \%)$ at T1 (T0 vs. T1 chi square with Yates' correction 4.875 , $1 \mathrm{df}$, $\mathrm{p}=0.0027) ; 17(43.6 \%)$ at $\mathrm{T} 2$ (T0 vs. T2 chi square with Yates' correction $4.875,1 \mathrm{df}, \mathrm{p}=0.0027)$.

Table 3a. T1- Subjects with SF-12 scores higher than 42 (average plus one standard deviation from the normative sample stratified by sex and age).

\begin{tabular}{|c|c|c|}
\hline & SF-12 $>$ mean + 1 SD & SF-12 < mean + 1 SD \\
\hline \hline $\begin{array}{c}\text { Cortisol }<200 \\
\text { or }>300\end{array}$ & $11(57.9 \%)$ & 8 \\
\hline $\begin{array}{c}\text { Cortisol } \\
\text { between } 200-300\end{array}$ & $5(25 \%)$ & 15 \\
\hline
\end{tabular}

Chi square with Yates' correction 4.35, $\mathrm{p}<0.036$.

Table 3b. T2- Subjects with SF-12 score higher than 42 (average plus one standard deviation from the normative sample stratified by sex and age).

\begin{tabular}{|c|c|c|}
\hline & SF-12 $>$ mean + 1 SD & SF-12 < mean + 1 SD \\
\hline \hline $\begin{array}{c}\text { Cortisol }<200 \\
\text { or }>300\end{array}$ & $9(69.2 \%)$ & 4 \\
\hline $\begin{array}{c}\text { Cortisol } \\
\text { between } 200-300\end{array}$ & $10(37.0 \%)$ & 17 \\
\hline
\end{tabular}

Chi square with Yates' correction 3.81, 1df, p $<0.05$.

No differences were found in the distribution of subjects with more than $200 \mathrm{mg} / \mathrm{ml}$ of blood cortisol levels according to group at the three observation times [T0: $\mathrm{PGG}=4(20 \%)$, $\mathrm{VAG}=3 \quad(15.8 \%)$ : Yates' $\chi^{2}=0.006, \mathrm{p}=0.938 ; \mathrm{T} 1: \mathrm{PGG}=11$ $(55 \%), \quad \mathrm{VAG}=6 \quad(31.6 \%): \quad$ Yates' $\chi^{2}=0.132, \quad \mathrm{p}=0.249$; T2: $\mathrm{PGG}=9$ (45\%), $\mathrm{VAG}=8 \quad(42.1 \%):$ Yates' $\chi^{2}=0.002$, $\mathrm{p}=0.887$ ] (Table 4a).

Subjects with cortisol levels between 200 and $300 \mathrm{mg} / \mathrm{ml}$ numbered $7(36.8 \%)$ at T0, $13(26.5 \%)$ at $\mathrm{T} 1$ (T0 vs. T1 chi square with Yates' correction 2.421, $1 \mathrm{df}, \mathrm{p}=0.119)$ and 16 $(41.0 \%)$ at T2 (T0 vs. T2 chi square with Yates' correction $4.994,1 \mathrm{df}, \mathrm{p}=0.025$ ). The distribution of subjects with cortisol levels between 200 and $300 \mathrm{mg} / \mathrm{ml}$ according to group showed no differences at the three observation times [T0: $\mathrm{PGG}=4(20 \%), \mathrm{VAG}=3(15.8 \%)$ : Yates' $\chi^{2}=0.006, \mathrm{p}=0.938$; T1: $P G G=7 \quad(35 \%), \quad V A G=6 \quad(31.6 \%)$ : Yates' $\chi^{2}=0.013$, $\mathrm{p}=0.909 ; \quad \mathrm{T} 2: \quad \mathrm{PGG}=9 \quad(45 \%), \quad \mathrm{VAG}=7 \quad(36.8 \%):$ Yates' $\left.\chi^{2}=0.604, p=0.847\right]$ (Table $\left.4 \mathbf{b}\right)$.

\section{DISCUSSION}

The study shows that both at the end and 12 weeks after a trial proposing different exercise levels, a sample of older people increased their blood levels of cortisol, reaching, in most subjects, a higher but not pathological level. These changes appear to be related to changes in the perception of the Quality of Life.
In the group of elderly subjects undergoing vigorous exercise, at the end of the trial, blood cortisol levels were higher than those prior to beginning the trial, along with a better perception of the Quality of Life than the score for a normative national sample. Twelve weeks after the end of the trial, both cortisol levels and scores regarding the Quality of Life decreased, but remained higher, with statisticallysignificant differences, when compared, respectively, both to basal cortisol levels and to the level of the Quality of Life for the normative sample.

In the group of elderly subjects undergoing moderate exercise, blood cortisol levels were higher at the end of the trial than prior to its start, just as the Quality of Life score was higher than the score for the normative national sample, with statistically significant differences in both cases. Twelve weeks after the end of the trial, both cortisol levels and Quality of Life scores decreased, reaching levels and scores with no statistically-significant differences compared, respectively, both to doses of basal cortisol as well as to the level of the Quality of Life for the normative sample.

Subjects with cortisol levels $\geq 200 \mathrm{mg} / \mathrm{ml}$ were higher at $\mathrm{T} 1$ and $\mathrm{T} 2$ than at $\mathrm{T} 0$.

Subjects with cortisol levels $\geq 200 \mathrm{mg} / \mathrm{ml}$ in both groups showed no difference in SF-12 scores as compared to subjects with less than $200 \mathrm{mg} / \mathrm{ml}$ at T1, but they reported Quality of Life scores higher than those with less than $200 \mathrm{mg} / \mathrm{ml}$ at $\mathrm{T} 2$.

This seemingly contradictory result must be assessed in light of the fact that some individuals, including those with cortisol levels of more than $200 \mathrm{mg} / \mathrm{ml}$, showed a blood cortisol level above 300, which can be judged to be in the pathological range.

At both T1 and T2, a better perception of the Quality of Life (SF-12 with a score of one standard deviation higher than the normalized national average) was in fact more common among those who had a cortisol levels between 200 and $300 \mathrm{mg} / \mathrm{ml}$.

Subjects with cortisol levels between 200 and $300 \mathrm{mg} / \mathrm{ml}$ increased from $\mathrm{T} 0$ to $\mathrm{T} 1$, but only at $\mathrm{T} 2$ was the difference higher at a significant statistical level as compared to $\mathrm{T} 0$.

It could therefore be hypothesized that exercise, in some specific cases, could excessively increase the cortisol level and, for this reason, results might be better in these cases 12 weeks after the end of the survey. However, it could alternatively be speculated that it was not exercise that directly caused the increase in cortisol between $\mathrm{T} 0$ and $\mathrm{T} 2$, if the increase at T0, T1 and T2 was linear. However, other papers have confirmed that exercise is one factor that can determine an increase in cortisol, but that it interacts with other determinants of cortisol levels, such as stressful events [5]. Older adults with higher levels of stress demonstrated a significantly higher cortisol/DHEA ratio. Individuals with higher stress incidence who did not train aerobic exercise had a significantly higher cortisol/DHEA ratio and a flatter DHEA diurnal rhythm as compared with those who regularly did so [5].

One could assume at least two distinct cortisol-action mechanisms in the perception of well-being in the elderly: 
Table 4a. Distribution of subjects with cortisol blood levels $>200 \mathbf{~ m g} / \mathbf{m l}$ according to group at the three observation times.

\begin{tabular}{|c|c|c|c|c|}
\hline Time (N, \%) & VAG & PGG & ${\text { Yates' } \mathbf{X}^{2}}^{\text {p value }}$ \\
\hline \hline $\mathrm{T} 0(\mathrm{~N}=7,36.8 \%)$ & $3(15.8 \%)$ & $4(20 \%)$ & 0.006 & 0.938 \\
\hline $\mathrm{T} 1(\mathrm{~N}=17,43.6 \%)$ & $6(31.6 \%)$ & $11(55 \%)$ & 0.132 & 0.249 \\
\hline $\mathrm{T} 2(\mathrm{~N}=17,43.6 \%)$ & $8(42.1 \%)$ & $9(45 \%)$ & 0.002 & 0.887 \\
\hline
\end{tabular}

Table 4b. Distribution of subjects with cortisol blood levels $>200 \leq 300 \mathrm{mg} / \mathrm{ml}$ according to group at the three observation times.

\begin{tabular}{|c|c|c|c|c|}
\hline Time (N, \%) & VAG & PGG & ${\text { Yates' } \mathbf{X}^{2}}^{\text {p value }}$ \\
\hline \hline $\mathrm{T} 0(\mathrm{~N}=7,36.8 \%)$ & $3(15.8 \%)$ & $4(20 \%)$ & 0.006 & 0.938 \\
\hline $\mathrm{T} 1(\mathrm{~N}=13,26.5 \%)$ & $6(31.6 \%)$ & $7(35 \%)$ & 0.013 & 0.909 \\
\hline $\mathrm{T} 2(\mathrm{~N}=16,41.0 \%)$ & $7(36.8 \%)$ & $9(45 \%)$ & 0.604 & 0.847 \\
\hline
\end{tabular}

first, the role of cortisol in the formation of steroid hormones deriving from progesterone, and secondly, the direct effect of cortisol on the attenuation of stress, also related to the endocannabinoid system.

It has been hypothesized that neurosteroids deriving from progesterone may play a role as endo-mood stabilizers [8], and high levels of 3alpha-hydroxy-5alpha-pregnan-20-one (3alpha,5alpha-THPROG) and 3alpha,21-dihydroxy-5alphapregnan-20-one have been found in women with bipolar disorder, clinically compensated for and in symptomatic remission [20]. Not much is known about how cortisol might influence the level of neuroactive steroid hormones deriving from progesterone, or rather their analogues sulfates, or testosterone, which apparently have a different effect on mood [21]. Indeed, a recent study found that in the elderly, the perception of Quality of Life was not affected by testosterone levels [22]. Among adolescents, cortisol has been found to be positively associated with DHEA slopes, and negatively associated with testosterone [23]. As the level of testosterone decreases with age, it is therefore possible that an increase in cortisol in the elderly can lead to a more marked increase in progesterone derivatives.

A direct role of cortisol in modulating stress was also shown; in particular, cortisol and endocannabinoid systems seem to interact in stimulating "positive memories" after stressful events [1]. Several studies showed that administering cortisol to seriously ill or injured subjects produces a significant reduction of PTSD symptoms after recovery, without affecting the number of trauma memories [1].

A recent paper reviewed the role of glucocorticoids and glucocorticoid receptors (GRs) in memory formation and modulation [2], highlighting the evidence on the molecular events at the basis of GRs activation effect during moderate stress, promoting long-duration memory. Such effect could mainly involve the brain-derived neurotrophic factor (BDNF), because, after stress-induced learning, the activation of hippocampal GRs might determine the activation of the BDNF/cAMP response element-binding protein (CREB) pathway, the general mechanism promoting the consolidation of long-term memory [2]. According to this hypothesis, exercise could moderately increase cortisol levels, which might improve coping with daily stress in the elderly, and might protect against the effects of chronic stress by counteracting a stress-related decrease in hippocampal BDNF mRNA.

\section{LIMITATIONS}

The sample was small; the perception of Quality of Life was not measured at the beginning of the trial, as the "A Chent'annos in Salude" trial was not specifically designed to address the issue of how exercise might induce both an increase in blood cortisol levels and a better subjective Quality of Life. Thus, the association among exercise, the perception of Quality of Life and the moderate increase in cortisol levels in the elderly suggested by this research must be taken into account as only a heuristic hypothesis. Nevertheless, if confirmed, these results could represent a first step in better understanding the relationship between physical activity and well-being in elderly people.

\section{CONCLUSION}

The results of this study appear to demonstrate that exercise moderately increases blood cortisol levels in the elderly, and that this increase is related to the perception of a high Quality of Life. More sustained exercise extends both the increase in cortisol levels and improvement in the perception of the Quality of Life. Future research using larger samples and stronger methodologies is needed to confirm the relationship among cortisol, exercise and perception of the Quality of Life suggested by this study.

\section{CONFLICT OF INTEREST}

The authors confirm that this article content has no conflict of interest.

\section{ACKNOWLEDGEMENTS}

The authors wish to thank the President of CONI (Italian Olympic Committee) Sardinia, Gianfranco Fara, for his ef- 
forts to support the research. We are also grateful to all the athletic trainers and the participants that have made possible the conduct of the trial.

\section{REFERENCES}

[1] Hauer D, Kaufmann I, Strewe C, Briegel I, Campolongo P, Schelling G. The role of glucocorticoids, catecholamines and endocannabinoids in the development of traumatic memories and posttraumatic stress symptoms in survivors of critical illness. Neurobiol Learn Mem 2014; 112C: 68-74.

[2] Finsterwald C, Alberini CM. Stress and glucocorticoid receptordependent mechanisms in long-term memory: from adaptive responses to psychopathologies. Neurobiol Learn Mem 2014; 112C: 17-29.

[3] Carta MG, Balestrieri M, Murru A, Hardoy MC. Adjustment Disorder: epidemiology, diagnosis and treatment. Clin Pract Epidemiol Ment Health 2009; 5: 15.

[4] Kudielka BM, Hellhammer DH, Wüst S. Why do we respond so differently? Reviewing determinants of human salivary cortisol responses to challenge. Psychoneuroendocrinology 2009; 34(1): $2-18$.

[5] Heaney JL, Carroll D, Phillips AC. Physical activity, life events stress, cortisol, and DHEA in older adults: preliminary findings that physical activity may buffer against the negative effects of stress. J Aging Phys Act 2013 [Epub ahead of print]

[6] Heaney JL, Phillips AC, Carroll D. Ageing, physical function and the diurnal rhythms of cortisol and dehydroepiandrosterone. Psychoneuroendocrinology 2012; 37(3): 341-9.

[7] Selye H. Stress and distress. Compr Ther 1975; 1(8): 9-13.

[8] Mantovani G, Astara G, Lampis B, et al. Evaluation by multidimensional instruments of heath-related quality of life of elderly cancer patients undergoing three different "psychosocial" treatment approaches. A randomized clinical trial. Support Care Cancer 1996; 4(2): 129-40.

[9] Mantovani G, Astara G, Lampis B, et al. Impact of psychosocial intervention on the quality of life of elderly cancer patients. Psycho-Oncology 1996; 5: 127-35.

[10] Mura G, Bhat KM, Pisano A, Licci G, Carta MG. Psychiatric symptoms and quality of life in systemic sclerosis. Clin Pract Epidemiol Ment Health 2012; 8: 30-5.

[11] Carta MG, Hardoy MC, Pilu A, et al. Improving physical quality of life with group physical activity in the adjunctive treatment of ma- jor depressive disorder. Clin Pract Epidemiol Ment Health 2008; 4: 1.

[12] Pilu A, Sorba M, Hardoy MC, et al. Efficacy of physical activity in the adjunctive treatment of major depressive disorders: preliminary results. Clin Pract Epidemiol Ment Health 2007; 3: 8.

[13] Mura G, Sancassiani F, Migliaccio GM, Collu G, Carta MG. The association between different kinds of exercise and quality of life in the long term. Results of a randomized controlled trial on the elderly. Clin Pract Epidemiol Ment Health 2014; 10: 36-41.

[14] Physical Activity Guidelines for Older Adults (65+ years). Available online: https://www.gov.uk/government/uploads/system/ uploads/attachment_data/file/213741/dh_128146.pdf [Accessed on: $7^{\text {th }}$ March 2014]

[15] Grundy SM, Cleeman JI, Daniels SR, et al. American Heart Association; National Heart, Lung, and Blood Institute. Diagnosis and management of the metabolic syndrome: an American Heart Association/National Heart, Lung, and Blood Institute Scientific Statement. Circulation 2005; 112(17): 2735-52.

[16] American College of Sports Medicine. ACSM's guidelines for exercise testing and prescription: Lippincott Williams \& Wilkins 2013.

[17] Gellish RL, Goslin BR, Olson RE, McDonald A, Russi GD, Moudgil VK. Longitudinal modelling of the relationship between age and maximal heart rate. Med Sci Sports Exerc 2007; 39(5): 822-9.

[18] Ware J Jr, Kosinski M, Keller SD. A 12-Item Short-Form Health Survey: construction of scales and preliminary tests of reliability and validity. Med Care 1996; 34: 220-33.

[19] Carta MG, Aquqlia E, Caraci F. et al. Quality of life and urban/ rural living: preliminary results of a community survey in Italy. Clin Pract Epidemiol Ment Health 2012; 8: 169-74.

[20] Hardoy MC, Serra M, Carta MG, Contu P, Pisu MG, Biggio G. Increased neuroactive steroid concentrations in women with bipolar disorder or major depressive disorder. J Clin Psychopharmacol 2006; 26(4): 379-84.

[21] Carta MG, Bhat KM, Preti A. GABAergic neuroactive steroids: a new frontier in bipolar disorders? Behav Brain Funct 2012; 8: 61

[22] Glintborg D, Nielsen TL, Wraae K, et al. The relationship between health-related Quality of Life, obesity and testosterone levels in older men. Age Ageing 2014; 43(2): 280-4.

[23] Marceau K, Ruttle PL, Shirtcliff EA, Hastings PD, Klimes-Dougan B, Zahn-Waxler C. Within-person coupling of changes in cortisol, testosterone, and DHEA across the day in adolescents. Dev Psychobiol 2013. doi: 10.1002/dev.21173 [Epub ahead of print]

(C) Mura et al.; Licensee Bentham Open.

This is an open access article licensed under the terms of the Creative Commons Attribution Non-Commercial License (http://creativecommons.org/licenses/by-nc/3.0/) which permits unrestricted, non-commercial use, distribution and reproduction in any medium, provided the work is properly cited. 